\title{
PENYULUHAN MENGENAI EKOSISETEM LAMUN SEBAGAI UPAYA PELESTARIAN EKOSISTEM DI PERAIRAN PANTAI SIRE, KABUPATEN LOMBOK UTARA
}

\author{
Ibadur Rahman *), Baiq Hilda Astriana \\ Jurusan Perikanan dan IImu Kelautan, Universitas Mataram \\ Jalan Pendidikan Nomor 37, Mataram \\ *alamat korespondensi: ibadur.rahman@unram.ac.id
}

\begin{abstract}
ABSTRAK
Padang lamun merupakan salah satu ekosistem laut yang berperan penting bagi kehidupan biota laut. Padang lamun dimanfaatkan sebagai tempat untuk mencari makan, tempat pemijahan dan daerah asuhan berbagai jenis biota. Dewasa ini ekosistem lamun terus menerus mendapatkan tekanan yang mengancam kelestariannya (Bengen, 2004), baik diakibatkan fenomena alam atau karena aktivitas manusia. Sementara itu, tidak semua masyarakat pesisir memahami manfaat dari ekosistem lamun ini. Salah satu upaya yang dapat dilakukan untuk menjaga keberlangsungan ekosistem lamun yaitu dengan menanamkan kesadaran kepada masyarakat pesisir mengenai jenis-jenis, manfaat, status dan ancaman terhadap ekosistem lamun serta melakukan pendataan (monitoring) ekosistem lamun, dengan melibatkan masyarakat tersebut. Metode yang digunakan dalam kegiatan pengabdian ini berupa penyuluhan oleh narasumber dengan kepakaran di bidang tersebut dan diskusi mengenai peranan ekosistem lamun dan ancaman yang sedang dihadapi, serta simulasi pengamatan tutupan lamun dan identifikasi jenis lamun. Hasil dari kegiatan pengabdian ini menunjukkan bahwa masyarakat memiliki antusias yang tinggi untuk terlibat aktif dalam upaya pelestarian ekosistem lamun dan hasil monitoring menunjukkan bahwa kondisi lamun di lokasi kegiatan termasuk dalam kategori sehat.
\end{abstract}

Kata kunci: ekosistem lamun, pantai sire, monitoring

\section{PENDAHULUAN}

Padang lamun sebagai salah satu komponen dalam ekosistem pesisir (Tangke, 2010) memiliki peranan vital bagi biota-biota asosiasi yang hidup di sekitarnya. Beberapa fungsi ekologis padang lamun di antaranya sebagai produsen primer, pemecah arus, penstabil substrat, habitat serta makanan bagi organisme laut yang lain (Hartati et al., 2012; Aswandy \& Azkab, 2000; Feryatun, 2012).

Masyarakat awam umumnya menganggap ekosistem lamun sama 
halnya seperti tumbuhan rumput liar yang hidup di daratan. Anggapan ini menyebabkan lamun dianggap sebagai tanaman pengganggu yang dapat mengurangi keindahan pemandangan bawah laut yang menjadi komoditi pariwisata, layaknya ekosistem terumbu karang dengan populasi ikanikan karang yang beraneka ragam dan warnanya.

Saat ini ekosistem padang lamun terus menerus mendapatkan tekanan yang mengancam kelestariannya (Bengen, 2004). Rendahnya pemahaman masyarakat terhadap keberadaan dan kebermanfaatan ekosistem lamun menjadikannya hanya dipandang sebelah mata, bahkan banyak dijumpai kegiatan-kegiatan masyarakat yang berpotensi mengancam kelestarian ekosistem lamun, misalnya: penangkapan ikan menggunakan pukat dasar (trawl) yang tidak spesifik menangkap ikan, namun turut menjaring tumbuhan lamun, kegiatan pengerukan dan pengurugan pantai, ramainya lalu lintas kapal, serta polusi dan limbah baik domestik maupun limbah pabrik yang dibuang ke laut sehingga dapat mencemari perairan.

Masyarakat pesisir merupakan ujung tombak dalam upaya pelestarian ekosistem lamun. Hal ini dikarenakan masyarakat sekitar lah yang selalu berinteraksi dengan ekosistem lamun, yang ikut andil dalam upaya memperbaiki atau bahkan memperburuk kondisi eksisting ekosistem lamun. Peningkatan wawasan masyarakat terhadap peran ekosistem lamun, baik sebagai feeding ground, spawning ground dan nursery ground, ditambah fungsi fisik lamun sebagai perangkap sedimen akan mengakibatkan bertambahnya kesadaran masyarakat untuk ikut menjaga dan melestarikan ekosistem lamun.

Maka dari itu, kegiatan pengabdian ini berupaya memberikan pemahaman yang lebih baik melalui kegiatan penyuluhan kepada masyarakat mengenai jenis-jenis, manfaat, status dan ancaman ekosistem lamun serta pendampingan untuk monitoring kondisi ekosistem lamun. Setelah diselenggarakannya kegiatan pengabdian ini, masyarakat diharapkan dapat berperan aktif dalam upaya pelestarian ekosistem lamun dan mencegah upaya-upaya yang dapat merusak ekosistem lamun, baik yang disadari maupun tidak.

\section{METODE KEGIATAN}

Kegiatan pengabdian ini dilakukan pada tanggal 14 September 2019, di kawasan ekosistem lamun Pantai Sire, Desa Sigar Penjalin, Kabupaten Lombok Utara, Provinsi Nusa Tenggara Barat. Kegiatan pendampingan masyarakat dalam monitoring ekosistem lamun ini dibagi menjadi beberapa tahapan :

1) Survey Lokasi 
Survey lokasi meliputi kegiatan peninjauan ke lokasi pengabdian, menggali informasi hasil wawancara dengan masyarakat, dan studi literatur terhadap kegiatan penelitian atau pengabdian yang pernah dilakukan sebelumnya.

2) Pembuatan Pedoman Monitoring Lamun

Pembuatan pedoman monitoring lamun meliputi studi literatur mengenai jenis-jenis metode pengamatan lamun, serta menentukan metode yang paling sesuai dengan kondisi lokasi dan masyarakat.

3) Sosialisasi dan Pendampingan Masyarakat

Kegiatan sosialisasi meliputi perizinan ke Kepala Desa, penginformasian kepada masyarakat mengenai jadwal sosialisasi, penyampaian sosialisasi kepada masyarakat mengenai manfaat lamun, ancaman terhadap kerusakan lamun, dan bentuk-bentuk upaya pelestarian ekosistem lamun, serta kegiatan pelatihan pendataan lamun yang benar sesuai pedoman yang terstandarisasi. Adapun metode pemantauan (monitoring) ekosistem lamun yang digunakan mengacu pada standar internasional Seagrass Watch, menggunakan kuadran transek berukuran $50 \times 50 \mathrm{~cm}^{2}$ (Gambar 1). Dari kuadran tersebut kemudian dapat ditentukan berapa persentase penutupan lamun dan jenis apa saja yang ditemukan di kawasan Pantai Sire.

\section{4) Evaluasi}

Kegiatan evaluasi diperlukan untuk mengetahui seberapa efektif kegiatan penyuluhan dan pendampingan dalam kegiatan monitoring terhadap pemahaman dan kesadaran masyarakat dalam upaya melestarikan ekosistem lamun.

\section{HASIL DAN PEMBAHASAN}

Hasil dari kegiatan penyuluhan dan pendampingan ini diuraikan dalam beberapa tahapan sebagai berikut:

1) Survey Lokasi

Hasil survey lokasi menunjukkan bahwa Kawasan Pantai Sire merupakan salah satu kawasan wisata pantai yang berada di Kabupaten Lombok Utara dan selalu ramai dikunjungi oleh wisatawan. Dengan demikian, kawasan ini berpotensi mendapatkan ancaman dari aktivitas antropogenik terutama dari kegiatan wisata tersebut. 


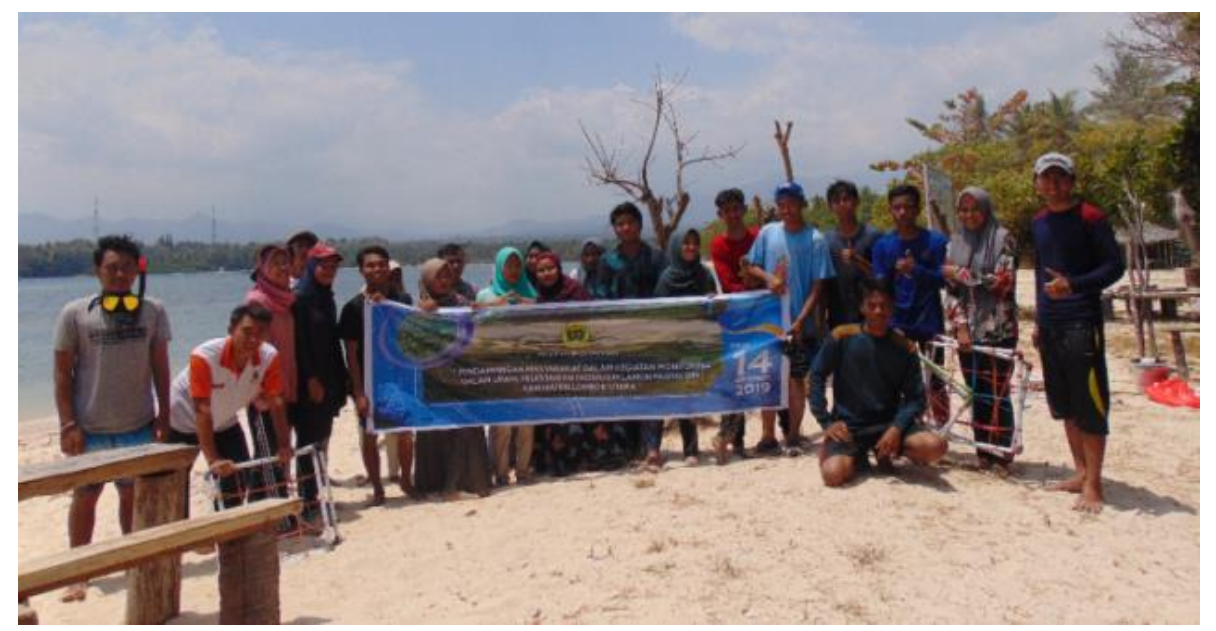

Gambar 1. Kegiatan Pemantauan (monitoring) ekosistem lamun Pantai Sire

2) Pembuatan Pedoman Monitoring Lamun

Pedoman kegiatan lamun yang dibuat terdiri dari acuan dalam mengidentifikasi jenis lamun yang ada di lokasi kegiatan. Selanjutnya masing-

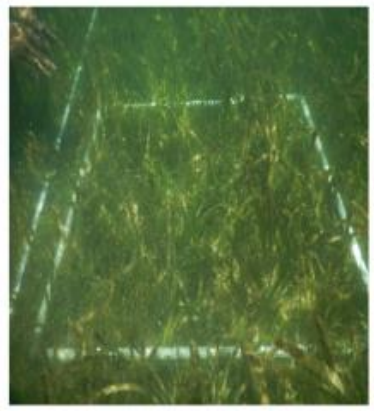

(a)

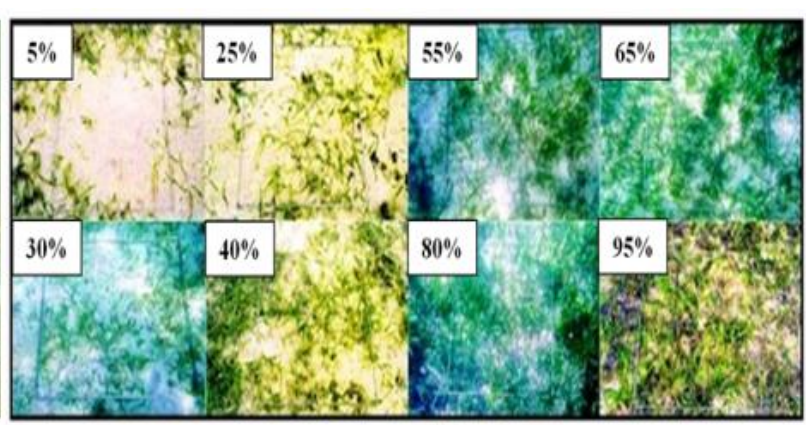

(b)

Gambar 2. (a) pengamatan tutupan dan jenis lamun menggunakan kuadran transek 50x50 cm², (b) Standar Perhitungan Persentase Penutupan Lamun Seagrass Watch (Short et al., 2004).

3) Sosialisasi dan Pendampingan Dipilihnya konstituen berusia muda Masyarakat

Kegiatan penyuluhan ini dikarenakan pada usia tersebut, masyarakat cenderung masih berpikir dihadiri oleh 30 peserta, yang idealis, realistis dan mudah diarahkan. keseluruhannya merupakan pemuda- Hal ini berkebalikan dengan prilaku pemudi berusia di bawah 30 tahun generasi tua ataupun paruh baya, yang yang berdomisili di sekitar kawasan cenderung berpikir pragmatis dan sulit ekosistem lamun Pantai Sire. untuk menerima informasi baru 
apalagi yang bertentangan dengna kebiasaan atau pengalaman mereka.

Pada kegiatan ini beberapa materi yang disampaikan kepada masyarakat antara lain peranan ekosistem lamun bagi ekosistem laut, beberapa jenis lamun, serta ancaman bagi keberlangsungan ekosistem lamun. Selain itu, dalam rangka kegiatan monitoring kondisi ekosistem lamun, maka diberikan materi mengenai cara mengidentifikasi spesies lamun dan cara menghitung persentase tutupan lamun dengan mengacu pada pedoman yang telah dibuat. Kegiatan ini sangat apresiasi oleh para peserta karena hampir seluruh peserta belum pernah mendapatkan wawasan mengenai materi-materi yang telah disampaikan.

Selain itu, rentang usia peserta kegiatan yang masih terbilang muda membuat proses penyuluhan dan pendampingan menjadi relatif mudah untuk dilakukan mengingat kemampuan mereka dalam menyerap materi yang diberikan relatif cepat.

4) Evaluasi

Hasil kegiatan pengabdian ini memperlihatkan antusiasme masyarakat, khususnya pemuda Desa Sigar Penjalin, dalam upaya pelestarian ekosistem lamun di kawasan Pantai Sire, Kabupaten Lombok Utara. Antusiasme tersebut dapat dilihat dari kesungguhan mereka dalam memperhatikan dan menyimak dengan seksama penjelasan dari nara sumber, serta mengikuti kegiatan simulasi pemantauan (monitoring) kondisi lamun di Pantai Sire dengan penuh perhatian.

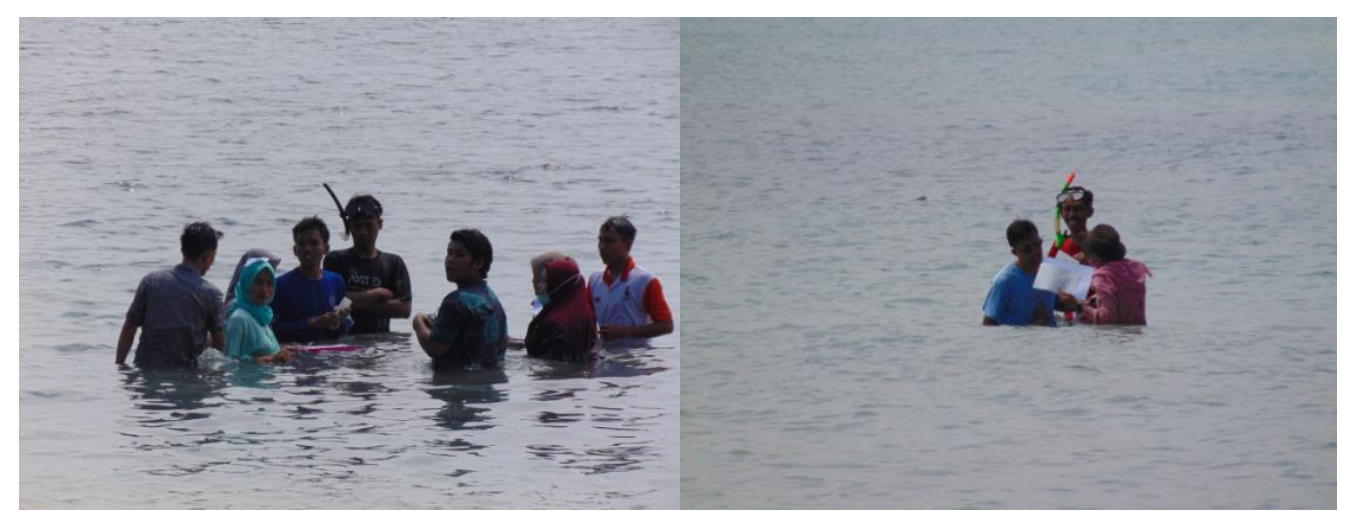

Gambar 3. Kegiatan monitoring ekosistem lamun

Sementara itu, berdasarkan dari 60 jenis lamun yang tersebar di hasil pemantauan yang dilakukan oleh seluruh dunia (Kuo \& McComb, 1989), peserta kegiatan dengan didampingi dan 15 jenis lamun yang ditemukan di oleh para pemateri, diketahui bahwa perairan wilayah Indonesia (Syafrie et 
al., 2018), peserta pengabdian berhasil mengkoleksi dan mengidentifikasi 8 (delapan) jenis lamun yang berada di kawasan padang lamun Pantai Sire, Kabupaten Lombok Utara, yaitu: Enh)lus acoroides (Ea), Syringodium isoetifolium (Si), Halodule pinifolia (Hp), Cymodocea rotundata (Cr), Thalassia hemprichii (Th), Halodule uninervis (Hu), Cymodocea serrulata (Cs) dan Halophila ovalis (Ho).

Hasil simulasi pengamatan tutupan tumbuhan lamun menggunakan transek kuadran 50x50 $\mathrm{cm}^{2}$ menunjukkan bahwa rerata tutupan lamun di kawasan Pantai Sire yaitu sebesar $71 \%$ (Tabel 1).
Berdasarkan Keputusan Menteri Kependudukan dan Lingkungan Hidup nomor 200/ 2004 (Syafrie et al., 2018) kondisi kondisi kesehatan lamun di kawasan Pantai Sire termasuk dalam kategori sehat (di atas 60\%). Dengan mengetahui status ekosistem lamun yang masih dalam kategori sehat tersebut, masyarakat diharapkan dapat berperan aktif dalam upaya menjaga dan mempertahankan kondisi ekosistem lamun di kawasan Pantai Sire agar selalu berada dalam kondisi sehat, serta mencegah upaya-upaya yang dapat menyebabkan kerusakan (degradasi) ekosistem lamun.

Tabel 1. Hasil simulasi pengamatan tutupan lamun Pantai Sire

\begin{tabular}{cccc}
\hline Pengamatan ke-1 & Pengamatan ke-2 & Pengamatan ke-3 & Rerata \\
\hline $68 \%$ & $84 \%$ & $60 \%$ & $71 \%$ \\
\hline
\end{tabular}

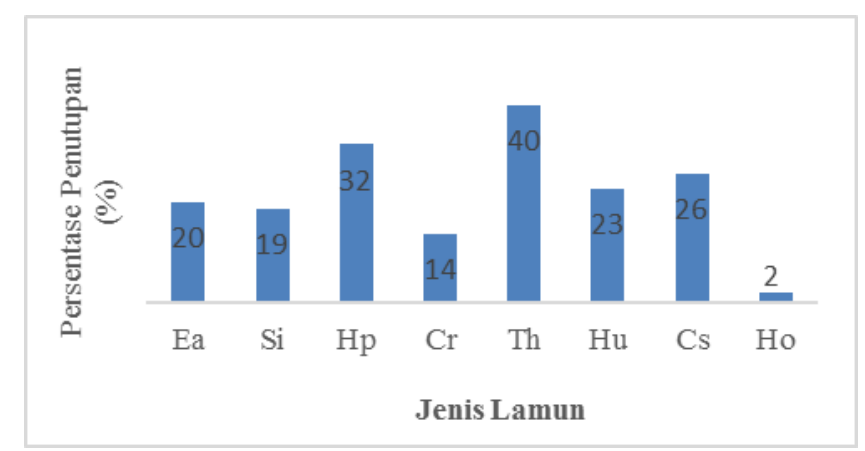

Gambar 4. Grafik penutupan jenis lamun yang ditemukan dalam kegiatan pemantauan (monitoring) ekosistem lamun kawasan Pantai Sire.

Berdasarkan pengamatan di ditemukan di padang lamun tersebut lapangan, ditemukan pula berbagai dikarenakan padang lamun merupakan jenis biota yang berada di area padang habitat bagi berbagai jenis biota, lamun, antara lain: bulu babi, teripang, ditambah fungsi lainnya baik sebagai kekerangan, dan beranekaragam jenis daerah asuhan, padang ikan. Beragamnya jenis biota yang 
penggembalaan dan tempat mencari makan (Syafrie et al., 2018).

Setelah mengetahui kondisi kesehatan lamun di kawasan Pantai Sire termasuk dalam kategori sehat, para peserta kegiatan menjadi termotivasi untuk terlibat aktif dalam upaya pelestarian ekosistem lamun. Keterlibatan masyarakat sekitar dalam upaya pelestarian ekosistem lamun menjadi sangat penting, mengingat mereka adalah orang-orang yang sehari-harinya berinteraksi dengan ekosistem lamun. Sehingga baik ataupun buruknya kondisi ekosistem lamun bergantung pada peran serta mereka dalam upaya menjaga, melestarikan dan memperbaiki kondisi ekosistem lamun, serta mencegah upaya-upaya yang bersifat merusak (mendegradasi) ekosistem lamun yang dilakukan oleh saudara dan kerabat mereka, atau dari pengunjung, baik disengaja ataupun tidak.

Adapun kendala yang dihadapi saat kegiatan berlangsung yaitu kondisi pasang air laut yang cukup mengganggu kegiatan pengamatan ekosistem lamun terutama bagi para peserta yang merupakan pemula. Selain itu, beberapa peserta yang tidak terbiasa menggunakan alat-alat yang dubutuhkan dalam kegiatan ini seperti snorkel dan masker mengalami kesulitan sehingga harus diberikan sedikit pelatihan mengenai cara menggunakan alat tersebut sebelum kegiatan monitoring dilakukan.
Kendala lainnya adalah para peserta belum bisa menghafal jenis-jenis lamun yang ada di buku pedoman, sehingga memperlambat kegiatan monitoring.

\section{KESIMPULAN DAN SARAN}

Berdasarkan hasil evaluasi, diketahui bahwa para peserta sangat merasakan manfaat dari kegiatan ini. Para peserta menyadari ancaman terhadap ekosistem lamun sebagai akibat dari aktivitas antropogenik serta pentingnya ekosistem lamun bagi keberlanjutan sumberdaya laut ke depannya. Sementara itu, terkait dengan kegiatan monitoring kondisi lamun di perairan Pantai Sira, kendala yang dihadapi yaitu kondisi air yang sudah pasang saat pengamatan dilakukan. Oleh karena itu, untuk kegiatan monitoring berikutnya faktor pasang-surut air laut di lokasi kegiatan akan dipertimbangkan.

\section{UCAPAN TERIMA KASIH}

Penulis mengucapkan terima kasih kepada Universitas Mataram yang telah memberi dukungan finansial melalui skema PNBP, sehingga kegiatan pengabdian ini dapat diselenggarakan dengan baik. Penulis mengucapkan terima kasih kepada mahasiswa Program Vokasi KLU Unram, dan mahasiswa Jurusan Perikanan dan Ilmu Kelautan Unram : Abdurrahman, Pandu AP, M. Supiandi, 


\section{DAFTAR PUSTAKA}

Agustina R, Faradilla A, Sultan HMT, Hardiawan, Azilia R, Idrus, Yuni PA, dan Hardi A.

Bengen. 2004. Ekosistem dan Sumberdaya Alam Pesisir dan Laut serta Prinsip Pengelolaannya. Pusat kajian Sumberdaya Pesisir dan Lautan. Institut Pertanian Bogor, Bogor.

Feryatun, F. 2012. Kerapatan dan

Distribusi Lamun (Seagrass) berdasarkan Zona Kegiatan yang berbeda di Perairan Pulau Pramuka, Kepulauan Seribu. Management of Aquatic Resources Journal, 1 (1): 44-50. Hartati, R., Djunaedi, A., Hariyadi \& Mujiyanto. 2012. Struktur Komunitas Padang Lamun di Perairan Pulau Kumbang, Kepulauan Karimunjawa. IImu Kelautan, 17 (4): 217-225.

Iswandy, I. \& Azkab, M. H. 2000. Hubungan Fauna dengan Padang Lamun. Oseana, 25 (3): 19-24.
Kuo, J., McComb, A.J. 1989. Seagrass Taxonomy, Structure and Development. In: Larkum, A.W.D., McComb, A.J., Shephard, S.A. (eds.). Biology of Seagrasses. $A$ treatise on the biology of seagrasses with special reference to the Australian region. Amsterdam: Elsevier.

Short F.T., L.J Mc Kenzie, R.G. Coles and J.L. Gaeckle. 2004. Seagrass Net Manual for Scientific Monitoring of Seagrass HabitatWestern Pacific Edition. USA. University of New Hampshire, QDPI, Northern Fisheries Center, Australia.

Syafrie N.D.M, U.E. Hernawan, B. Prayudha, I.H. Supriyadi, M.Y. Iswari, Rahmat, K. Anggraini, S. Rahmawati, Suyarso. 2018. Status Padang Lamun Indonesia 2018 Ver.02. Pusat Penelitian Oseanografi - LIPI : Jakarta Utara. Tangke, U. 2010. Ekosistem Padang Lamun (manfaat, fungsi dan rehabilitasi). Jurnal Agribisnis Perikanan, 3 (1): 9-29. 